\title{
Developing a Mathematical Model for Scheduling and Determining Success Probability of Research Projects Considering Complex-Fuzzy Networks
}

\author{
Gholamreza Norouzi, Mehdi Heydari, Siamak Noori, and Morteza Bagherpour \\ Department of Industrial Engineering, Iran University of Science and Technology, Narmak, Tehran 1684613114, Iran \\ Correspondence should be addressed to Gholamreza Norouzi; pey.gho@gmail.com
}

Received 23 January 2015; Revised 25 June 2015; Accepted 25 June 2015

Academic Editor: Ching-Jong Liao

Copyright (C) 2015 Gholamreza Norouzi et al. This is an open access article distributed under the Creative Commons Attribution License, which permits unrestricted use, distribution, and reproduction in any medium, provided the original work is properly cited.

\begin{abstract}
In project management context, time management is one of the most important factors affecting project success. This paper proposes a new method to solve research project scheduling problems (RPSP) containing Fuzzy Graphical Evaluation and Review Technique (FGERT) networks. Through the deliverables of this method, a proper estimation of project completion time (PCT) and success probability can be achieved. So algorithms were developed to cover all features of the problem based on three main parameters "duration, occurrence probability, and success probability." These developed algorithms were known as PR-FGERT (Parallel and Reversible-Fuzzy GERT networks). The main provided framework includes simplifying the network of project and taking regular steps to determine PCT and success probability. Simplifications include (1) equivalent making of parallel and series branches in fuzzy network considering the concepts of probabilistic nodes, (2) equivalent making of delay or reversible-to-itself branches and impact of changing the parameters of time and probability based on removing related branches, (3) equivalent making of simple and complex loops, and (4) an algorithm that was provided to resolve no-loop fuzzy network, after equivalent making. Finally, the performance of models was compared with existing methods. The results showed proper and real performance of models in comparison with existing methods.
\end{abstract}

\section{Introduction}

Research and R\&D projects are often conducted initially to design and manufacture a product with certain capabilities. A major part of projects is conducted in research organizations and institutes especially military ones. These projects have certain features including $[1,2]$ (1) uncertainty in defining the activities, (2) unclear and uncertain results of activities, (3) uncertainty in time and cost of activities, (4) noniterative activities, (5) loops and iterations to previous activities, and (6) parallel paths. Due to such features, a certain technique is needed to deal with such projects under determined time and cost effectively. On the other hand, backwardness and longtime of undertaking project would lead into huge costs not forecasted in initial budget plan and organizations may face numerous problems.

In practice, the projects have been implemented through an uncertain environment that ambiguity is one of the major features of such environments. Uncertainty may be considered as a property of the system which is an indicative defect in human knowledge towards a system and its state of progression [3]. Introduction of uncertainty topic for the first time entitled probability and it was attributed to Aristotle. Meanwhile, there are various types of uncertainty in the real world including fuzzy and random and being uncertain that includes the former two items [4]. Along with randomization, fuzziness is introduced as a fundamental type of subjective uncertainty [5].

In the early 20th century, Henry Gant and Frederick Taylor introduced Gantt chart which showed start and end of projects. However, overall timescale of the projects based on precedence relationships and analyses was not possible by this technique. Therefore, network designing in project control and design to remove raised problems and providing a more comprehensive technique was developed by a group of operation research (OR) scientists in 1950 and different 
methods, that is, CPM (Critical Path Method) and PERT (Program Evaluation and Review Technique), were introduced and developed [6].

Project management, in particular, project planning, is a critical factor in the success or failure of new product development (NPD) [7] and research and development (R\&D) projects [8]. Limited facilities of CPM and PERT methods for modeling of projects having complex and uncertain networks [6] caused the great scientists such as Pritsker and Whitehouse [9] and Pritsker and Happ [10] to introduce the probability GERT (Graphical Evaluation and Review Technique) which is a method consisted of flow graph theory, moment generation functions, and PERT to solve problems with probability activities. Pritsker [11] developed GERT method and used it for different nodes and introduced use of simulation in that method. Of course it is pointed out that Pritsker and Whitehouse [9] used Maison's role which had been introduced in graph theory to solve probability networks. The pointed out probability methods are all based on probable distributions such as Beta $(\beta)$ or normal distribution which are used for estimation of project activities period. Thus, to use probable distributions, random samples, repeatability, and statistical deduction will be required.

When fuzzy theory was introduced and developed by Zadeh [12], scientists' and researchers' attention in the field of network and science engineering was gradually caught by the issue that they will be able to solve the problem of uncertainty in problems and also expressed problems by a fuzzy approach. Thus, for the first time, Chanas and Kamburowski [13] introduced a new technique called FPERT (Fuzzy Program Evaluation and Review Technique), in which by using fuzzy theory, the estimation of activities time and project completion time had been shown by triangular fuzzy numbers. Gazdik [14] presented another technique based on fuzzy sets and graph theory called FNET (fuzzy network). This is for estimation of activities time by use of algebraic operators and by deductive method in the projects without data. Itakura and Nishikawa [15] applied fuzzy concepts in GERT networks for the first time, and by replacing fuzzy parameters for probability parameters, presented FGERT (Fuzzy Graphical Evaluation and Review Technique). method of solution is similar to probability GERT, but it is different because fuzzy theory was used to review GERT networks. McCahon [16] presented FPNA (Fuzzy Project Network Analysis) technique to identify critical path and obtain total float value and probability time for project completion. Ten years after presentation of his first measures on fuzzy GERT, Cheng $[17,18]$ presented another method of solution. Of course this method was presented to solve problems of series systems reliability, in which merely Exclusive-or nodes were dealt with. Basis of his method is the same probable GERT, but it is only different in using fuzzy parameters instead of probable functions. Nasution [19] dealt with development of FNET technique. He solved fuzzy networks with the multicritical paths approach by using interactive differential fuzzy method in the network reversible computations. Chang et al. [20] considered projects of large size planning networks. When such projects are under uncertain conditions, then the techniques presented to solve timed networks become complicated and sometimes unsolvable. Thus, they presented a technique by merging comparison and composite methods and also by using fuzzy Delphi, which was efficient for solving problems with the foregoing features. Shipley et al. [21] presented a technique called Belief in Fuzzy Probabilities of Estimated Time (BFPET) which is based on the fuzzy logic, belief functions, and fuzzy probability distributions and development principle. Wang [22-24] dealt with development of fuzzy sets approach for planning product development projects of limited and imprecise data. The approach he adopted was in line with the works of Buckley [25] and Tatish, that is, use of trapezoidal fuzzy numbers and their computational procedure. Chanas and Zielinski [26], Chen and Huang [27], Chen and Hsueh [28], Fortin et al. [29], and Ke and Liu [30] dealt with the issue of critical path in the network of projects scheduling problem that contains fuzzy duration times of activities. All these studies represent activity duration times described by means of fuzzy sets however without any component of time dependency. Huang et al. [31] have studied the project scheduling problem in CPM networks with activity duration times that are both fuzzy and time dependent.

Some new analytical methods for determining the completion time of GERT-type networks have been proposed by Shibanov [32], Hashemin, and Fatemi Ghomi [33]. The main problem of these methods is high complexity of relations and computations in a network without loops. Kurihara and Nishiuchi [34] solved probability GERT networks by Monte Carlo simulation, and by this method, they could analyze specific kind of nodes present in GERT networks without loops (with loops [35]). Gavareshki [1] and Lachmayer et al. $[2,36,37]$ presented a new method to solve fuzzy GERT networks whose basis goes back to the method for solving CPM networks, that is, moving forward and implementation of fuzzy literature and inference of the nodes. Hashemin [38] provides an analytical procedure for this kind of networks by simplifying GERT networks. Shi and Blomquist [39] dealt with using matrix structures for solving time scheduling networks. By combination of fuzzy logic and DSM (Dependency Structure Matrix), he could introduce a new approach for solving problems on time scheduling of projects with uncertainty in periods of activities and uncertainty in overlapping the activities. Martínez León et al. [40, 41] present an analytical framework for effective management of projects with uncertain iterations in probable GERT networks. The framework is based on the Design Structure Matrix. As the introduced approach was new, it is capable of being developed in the fuzzy networks and uncertainty in the definition of activities.

Usual techniques are not able to estimate project completion time (PCT) of the projects that are executed for the first time or projects having computational problems $[8,42$, 43]. Therefore, only networking techniques with particular definitions on parallel nods and branches may be regressed and can create loops in fuzzy environment which provide proper timescale for these projects by using the capabilities of fuzzy sets and networks adapted to the attributes and features of these projects. Concerning the bottlenecks of these techniques, a new method is developed to resolve 
the problems of these networks and to understand them better. Thus, the objectives of this research are

(1) to apply three parameters, duration, occurrence probability, and success probability for each of the project activities, as well as use of trapezoidal fuzzy numbers to present duration, and probabilities to occurrence and success of activities,

(2) to present methods for equivalent making of parallel and series branches in fuzzy networks considering the meanings and concepts of deterministic and probabilistic nodes,

(3) to provide a new mathematical model for removing delay or reversible-to-itself branches in fuzzy networks,

(4) to provide a new mathematical model for removing simple and subindependent complex loops in fuzzy networks based on transformation to reversible-toitself branches,

(5) to provide an algorithm for estimating of PCT and scheduling of the simplified (no loops) fuzzy networks, based on equivalent making of parallel and series branches,

(6) to provide a new mathematical model for estimating of the probability of project success.

In Section 2, features of studied problem (PR-FGERT) are described. In Section 3, assumptions and parameters will be dealt with which we come across in the process of research stages. In Section 4, the analytical approach and proposed algorithm are described. In Section 5, a numerical case study is given, so that the algorithm efficiency is demonstrated. In Section 6, the proposed algorithm and solution model validation have been presented. Finally, the conclusion and future research are presented in Section 7.

\section{Problem Definition and Features of Studied Problem (PR-FGERT)}

As mentioned in literature review, the closest and the most compatible type of network to display R\&D projects is GERT network. Due to limitation of accessing time information on each activity, we used times of trapezoidal fuzzy. In most of the engineering applications, trapezoidal fuzzy numbers are used as they are simple to represent, are easy to understand, and have a linear membership function so that arithmetic computations can be performed easily [44]. These networks have capabilities such as different types of nodes, parallel branches between two nodes (various ways to do an activity and/or transition from one node to another one, Table 3), the existence of delay or reversible-to-itself branches as well as simple and mixed loops, precedence relationships to several nods, and the existence of several end nodes to describe and to convert a project to a model properly.

The main assumption of the research is the existence of three parameters $\left(p_{i j}^{2}, p_{i j}^{1}, \widetilde{t}_{i j}\right)$ for each activity where $\widetilde{t}_{i j}$ is duration of doing the activities as a trapezoidal fuzzy number, $p_{i j}^{1}$ is occurrence probability, and $p_{i j}^{2}$ is the probability of ending an activity successfully (this value is independent of other activities for different branches and activities).

Concerning GERT networks' features with fuzzy times as well as presented assumptions and parameters, the firsttime-executed project can be modeled easily. To resolve these networks so that they have high performance in terms of understanding deliverables and functionality, an algorithm is provided to resolve the probability and fuzzy of these networks by using an innovative technique. It also provides an estimation of PCT along with the probability of its successful ending.

\section{Model Assumptions and Parameters}

The assumptions and parameters used in this paper are as follows.

3.1. The Modeling Procedure Has Been Done according to the Following Assumptions.

(i) Activity of the network has a single source and a single sink node. If several initial nodes and some end nodes exist, they should be connected to a dummy node.

(ii) Input side of a node was applied of And, Exclusiveor, and Inclusive-or types; output side of a node was applied of deterministic and probabilistic types.

(iii) Uncertainty in estimating duration of activities is of positive trapezoidal fuzzy number.

(iv) Uncertainty in occurrence of activities is considered of probable type.

(v) Uncertainty in success of activities is considered of probable type.

(vi) In the project activities network, loops are considered.

(vii) Maximum number of parallel branches between two nodes is three.

(viii) The number of loops iteration is uncertain.

(ix) Establishing the law of independence between existing loops in the network.

3.2. Parameters. The parameters are as follows:

$X_{(i-j)}$ : output activity from node $i$ and input to node $j$.

$Z_{Y_{i}}$ : output set of activities from node $i$.

$\widetilde{t}_{(i-j)}$ : fuzzy duration of doing activity $X_{(i-j)}$.

$d t_{(i-j)}$ : defuzzy duration of doing activity $X_{(i-j)}$.

$p_{(i-j)}^{1}$ : occurrence probability of activity $X_{(i-j)}$.

$p_{(i-j)}^{2}:$ success probability of activity $X_{(i-j)}$.

$\ln _{(o-m)}$ : output loop from node $(m)$ and input to node (o).

$\ln _{(o-m)}^{i}$ : loop of level $i$ output from node $(m)$ and input to node $(o)$. 
$p_{\ln _{(o-m)}}^{1}$ : occurrence probability of loop $\ln _{(o-m)}$.

$p_{\ln _{(o-m)}}^{2}:$ success probability of loop $\ln _{(o-m)}$.

$X_{\ln _{(o-m)}}$ : set of activities in loop $\ln _{(o-m)}$.

$\widetilde{t}_{\ln _{(o-m)}}$ : time value of loop unit $\ln _{(o-m)}$.

$\widetilde{t}_{(i-j)}^{\prime}$ : fuzzy duration of activity $X_{(i-j)}$ after impact of first time delay loop.

$\widetilde{t}_{(i-j)}^{\prime \prime}$ : fuzzy duration of activity $X_{(i-j)}$ after impact of second time delay loop.

$S_{(i-j)}$ : set of activities in a path consisting of series branches.

$\tilde{t}_{T_{s}}$ : fuzzy duration of equivalent branch to series branches.

$p_{T_{s}}^{1}$ : occurrence probability of equivalent branch to series branches.

$p_{T_{s}}^{2}$ : success probability of equivalent branch to series branches.

$\tilde{t}_{T_{p}}$ : fuzzy duration of equivalent branch to parallel branches.

$p_{T_{p}}^{1}$ : occurrence probability of equivalent branch to parallel branches.

$p_{T_{p}}^{2}$ : success probability of equivalent branch to parallel branches.

3.3. Fuzzy Operations Used in the Proposed Solution Algorithm. Regarding $\widetilde{N}_{1}=\left(l_{1}, m_{1}, u_{1}, s_{1}\right)$ and $\widetilde{N}_{2}=\left(l_{2}, m_{2}, u_{2}\right.$, $s_{2}$ ) as two positive trapezoidal fuzzy numbers, the fuzzy operators are calculated as follows [44]:

$$
\begin{aligned}
& \text { Addition } \oplus: \widetilde{N}_{1} \oplus \widetilde{N}_{2} \\
& \qquad=\left(l_{1}+l_{2}, m_{1}+m_{2}, u_{1}+u_{2}, s_{1}+s_{2}\right)
\end{aligned}
$$

Substraction $\ominus: \widetilde{N}_{1} \ominus \widetilde{N}_{2}$

$$
=\left(l_{1}-s_{2}, m_{1}-u_{2}, u_{1}-m_{2}, s_{1}-l_{2}\right)
$$

Multiplication $\otimes: \widetilde{N}_{1} \otimes \widetilde{N}_{2}$

$$
\approx\left(l_{1} * l_{2}, m_{1} * m_{2}, u_{1} * u_{2}, s_{1} * s_{2}\right)
$$

$$
h \otimes \widetilde{N}_{2}=\left(h * l_{2}, h * m_{2}, h * u_{2}, h * s_{2}\right)
$$

Division $\oslash: \widetilde{N}_{1} \oslash \widetilde{N}_{2} \approx\left(\frac{l_{1}}{s_{2}}, \frac{m_{1}}{u_{2}}, \frac{u_{1}}{m_{2}}, \frac{s_{1}}{l_{2}}\right)$

$$
\begin{aligned}
\max & \left\{\widetilde{N}_{1}, \widetilde{N}_{2}\right\} \\
= & \left(\left(l_{1} \vee l_{2}\right),\left(m_{1} \vee m_{2}\right),\left(u_{1} \vee u_{2}\right),\left(s_{1} \vee s_{2}\right)\right) .
\end{aligned}
$$

\section{Analytical Approach and Methodology}

4.1. Conceptual Model. In this section, new parallel and reversible branches in the fuzzy GERT (PR-FGERT) are
TABLE 1: Added time in other branches separating from node (i). See Figure 11.

\begin{tabular}{lcc}
\hline $\begin{array}{l}\text { Qyt. of branch }(i i) \\
\text { occurrence }\end{array}$ & $\begin{array}{c}\text { Occurrence } \\
\text { probability }\end{array}$ & Added time \\
\hline 0 & $1-p_{i i}^{1}$ & 0 \\
1 & $p_{i i}^{1} \cdot\left(1-p_{i i}^{1}\right)$ & $\tilde{t}_{i i}$ \\
2 & $\left(p_{i i}^{1}\right)^{2} \cdot\left(1-p_{i i}^{1}\right)$ & $2 \cdot \widetilde{t}_{i i}$ \\
$\vdots$ & $\vdots$ & $\vdots$ \\
$N$ & $\left(p_{i i}^{1}\right)^{n} \cdot\left(1-p_{i i}^{1}\right)$ & $n \cdot \widetilde{t}_{i i}$ \\
$\vdots$ & $\vdots$ & $\vdots$ \\
\hline
\end{tabular}

presented to solve the problem defined in Section 2. In the presented analytical approach, the proposed algorithm consists of several steps so that a graphical presentation is shown in Figure 1 described in the following subsections. However, five main steps of the algorithm are as follows.

\subsection{Development of Relations and Executive \\ Stages of Algorithm}

4.2.1. Equivalent Making and Removing of Reversible-to-Itself Branches. Given Figure 2, for this type of branches, three parameters of fuzzy duration $\left(\tilde{t}_{i i}\right)$, occurrence probability $\left(p_{i i}^{1}\right)$, and success probability $\left(p_{i i}^{2}\right)$ are considered. Since it is not clear how many times these branches should be repeated to free the node and node output branches (i), thus the approach of elimination of this type of branches is defined as follows: these branches are considered as a random geometric variable called $\operatorname{Ge}\left(x ; p_{i i}^{1}\right)$, where $x$ indicates number of branch repeats (ii). Thus, to eliminate this type of branches, both of mean duration that can be added and change of occurrence probability of other output branches from the node $(i)$ should be calculated:

$$
\mathrm{Ge}\left(x ; p_{i i}^{1}\right)=\left(1-p_{i i}^{1}\right) \cdot{p_{i i}^{1}}^{1^{x}} ; \quad x=0,1,2,3, \ldots
$$

(i) Computing the average of added time in other separating branches from node (i) by elimination of branch (ii) is as follows.

According to Table 1, mean duration added can be calculated as follows:

$$
\begin{aligned}
\vec{t}_{i j}= & \left(0 \cdot\left(1-p_{i i}^{1}\right)\right) \oplus\left(\left(p_{i i}^{1}\right) \cdot\left(1-p_{i i}^{1}\right) \otimes \widetilde{t}_{i i}\right) \\
& \oplus\left(2\left(p_{i i}^{1}\right)^{2} \cdot\left(1-p_{i i}^{1}\right) \otimes \widetilde{t}_{i i}\right) \oplus \cdots \\
& \oplus\left(n\left(p_{i i}^{1}\right)^{n} \cdot\left(1-p_{i i}^{1}\right) \otimes \widetilde{t}_{i i}\right) \oplus \cdots \\
= & \sum_{x=0}^{\infty} \oplus\left(\left[x\left(p_{i i}^{1}\right)^{x} \cdot\left(1-p_{i i}^{1}\right)\right] \otimes \widetilde{t}_{i i}\right) .
\end{aligned}
$$

According to the $\left[\left(1-p_{i i}^{1}\right) \otimes \tilde{t}_{i i}\right]$ term, independent of $x$ too, we should exit it from summation and we have

$$
=\left(\sum_{x=0}^{\infty} x \cdot\left(p_{i i}^{1}\right)^{x}\right) \cdot\left(1-p_{i i}^{1}\right) \otimes \tilde{t}_{i i} .
$$




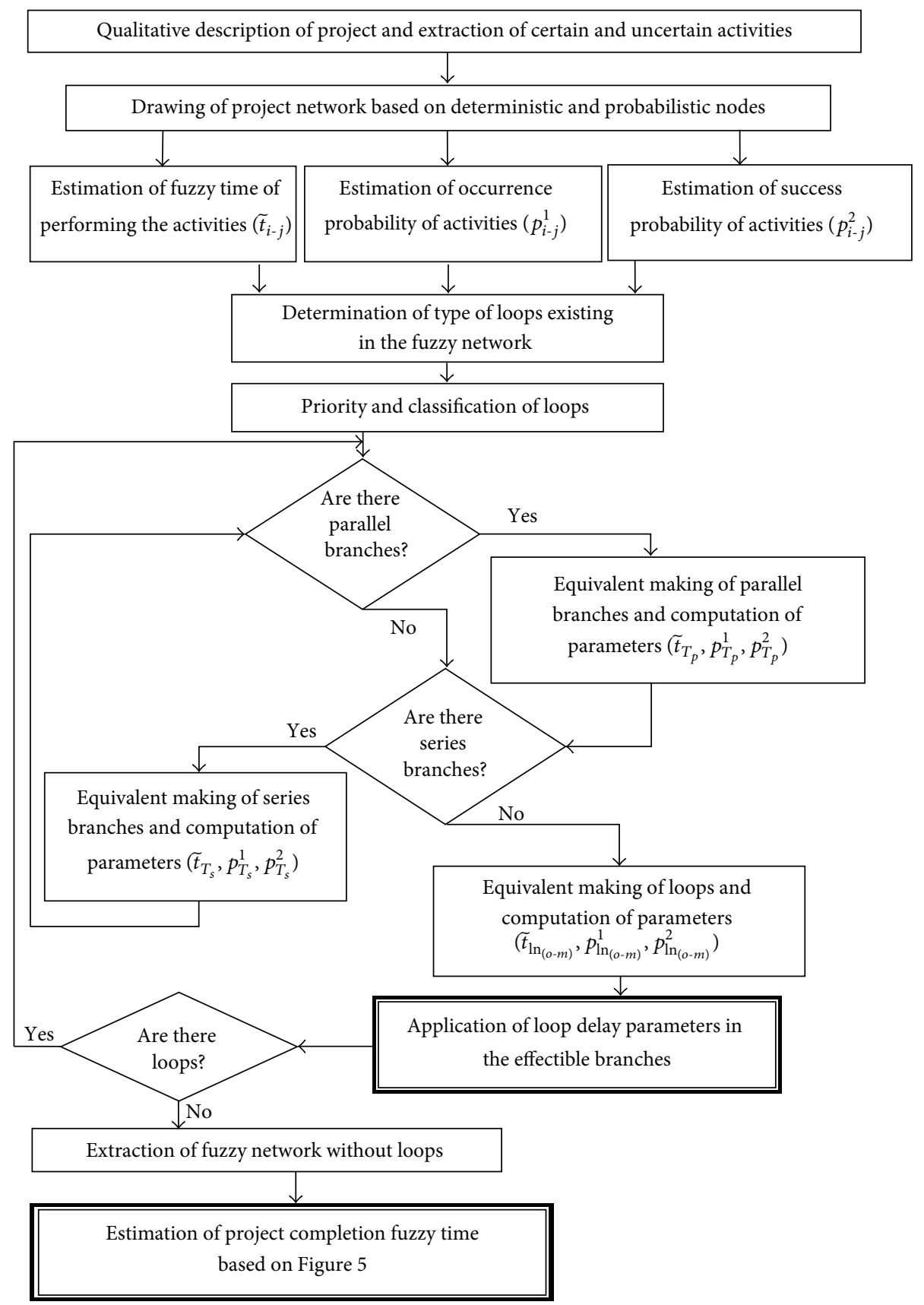

FIGURE 1: A graphical presentation of the proposed approach.

By exiting one $p_{i i}^{1}$ from summation, we have

$$
=\left(\sum_{x=1}^{\infty} x \cdot\left(p_{i i}^{1}\right)^{x-1}\right) \cdot p_{i i}^{1} \cdot\left(1-p_{i i}^{1}\right) \otimes \widetilde{t}_{i i}
$$

We assume that

$$
\Psi=\left(\sum_{x=1}^{\infty} x \cdot\left(p_{i i}^{1}\right)^{x-1}\right) \stackrel{\text { by expanding }}{\longrightarrow}\left[\Psi=\frac{1}{\left(1-p_{i i}^{1}\right)^{2}}\right] .
$$

By substituting of (6) in (5) and by simplifying, we have

$$
\vec{t}_{i j}=\frac{p_{i i}^{1}}{\left(1-p_{i i}^{1}\right)} \otimes \tilde{t}_{i i} .
$$

Therefore, after elimination of node ( $i$ ), the fuzzy duration resulting from (7) should be added to the duration of all output branches from node (i), in accordance with (8):

$$
\tilde{t}_{(k)}^{\prime}=\widetilde{t}_{(k)} \oplus\left[\left(\frac{p_{i i}^{1}}{1-p_{i i}^{1}}\right) \otimes \widetilde{t}_{i i}\right] ; \quad \forall k \in Z_{Y_{i}} .
$$




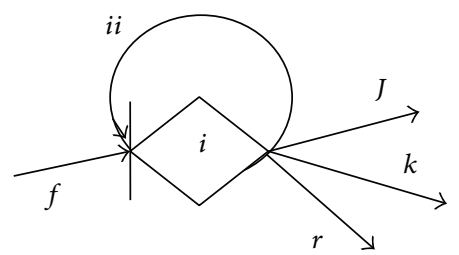

FIGURE 2: A display of delay branches.

(ii) Computing the change of success probability in other separating branches from node $(i)$ by elimination of branch (ii) is as follows.

To study the change of success probability in other branches from node (i) by elimination of branch (ii), assume that branch $(i-j)$ with parameters $\left(p_{i j}^{2}, p_{i j}^{1}, t_{i j}\right)$ is a branch of node $(i)$. Then, we have Table 2 .

According to Table 2, success probability can be calculated as follows:

$$
\begin{aligned}
p_{i j}^{2^{\prime}}= & p_{i j}^{2} \cdot\left(1-p_{i i}^{1}\right)+p_{i j}^{2} \cdot\left(p_{i i}^{2}\right) \cdot\left(p_{i i}^{1}\right) \cdot\left(1-p_{i i}^{1}\right)+p_{i j}^{2} \\
& \cdot\left(p_{i i}^{2}\right)^{2} \cdot\left(p_{i i}^{1}\right)^{2} \cdot\left(1-p_{i i}^{1}\right)+\cdots+p_{i j}^{2} \cdot\left(p_{i i}^{2}\right)^{n} \\
& \cdot\left(p_{i i}^{1}\right)^{n} \cdot\left(1-p_{i i}^{1}\right)+\cdots \\
= & \sum_{n=0}^{\infty} p_{i j}^{2} \cdot\left(p_{i i}^{2}\right)^{n} \cdot\left(p_{i i}^{1}\right)^{n} \cdot\left(1-p_{i i}^{1}\right) \\
= & p_{i j}^{2} \cdot\left(1-p_{i i}^{1}\right) \sum_{n=0}^{\infty}\left(p_{i i}^{2}\right)^{n} \cdot\left(p_{i i}^{1}\right)^{n} .
\end{aligned}
$$

Now, by expanding of (9) and simplifying it, we have

$$
\begin{array}{r}
\Longrightarrow p_{k}^{2^{\prime}}=p_{k}^{2} \cdot\left(1-p_{i i}^{1}\right) \cdot\left(1+\frac{\left(p_{i i}^{2}\right) \cdot\left(p_{i i}^{1}\right)}{1-\left[\left(p_{i i}^{2}\right) \cdot\left(p_{i i}^{1}\right)\right]}\right) \\
\forall k \in Z_{Y_{i}} .
\end{array}
$$

So we can conclude that success probability of each branch from node $(i)$ is multiplied in fixed value: $\left(1-p_{i i}^{1}\right)$. $\left(1+\left(\left(p_{i i}^{2}\right) \cdot\left(p_{i i}^{1}\right)\right) /\left(1-\left[\left(p_{i i}^{2}\right) \cdot\left(p_{i i}^{1}\right)\right]\right)\right)$.

(iii) Computing the change of occurrence probability in other separating branches from node $(i)$ by elimination of branch (ii) is as follows.
In order to calculate sum of probabilities of branches separating from node (i) after elimination of branch (ii) becomes one, the occurrence probability of each branch should be multiplied by value of

$$
\left(1+\frac{p_{i i}^{1}}{1-p_{i i}^{1}}\right)
$$

4.2.2. Equivalent Making of Parallel Branches between Two Nodes. According to assumption in present paper, there are maximum three, $a, b$, and $c$, branches with the fuzzy times of $\widetilde{t}_{a}=\left(a_{1}, a_{2}, a_{3}, a_{4}\right), \widetilde{t}_{b}=\left(b_{1}, b_{2}, b_{3}, b_{4}\right)$, and $\widetilde{t}_{c}=\left(c_{1}, c_{2}, c_{3}, c_{4}\right)$ between two nodes in parallel state. Then, for all activities based on the type of input and output nodes, the following states (Table 3 ) could be assumed.

(1) Parallel Branches between Two Nodes with "Probabilistic" Output and "Exclusive-Or" Input. In this state, among different ways to do an activity, only one way should be selected and implemented. To achieve the time of doing an equivalent activity, we used the average times based on occurrence probability since only one event occurs in each moment and, on the other hand, the branches are unknown. More occurrence probability of an activity would lead into its higher share in equating. In the meantime, the time of conducting each branch includes relevant time (in the case of successful conclusion) and also added time (in the case of nonconclusion of the branch). Since it was impossible to conduct other activities in that unit, the relevant time was computed based on time average of other moods. Therefore, the following can be extended by the above arguments:

$$
\begin{aligned}
\tilde{t}_{a} & =\frac{p_{a}^{1}}{p_{a}^{1}+p_{b}^{1}+p_{c}^{1}} \otimes\left[\tilde{t}_{a} \otimes p_{a}^{2} \oplus\left(1-p_{a}^{2}\right)\right. \\
& \left.\otimes\left(\begin{array}{l}
\frac{p_{b}^{1}}{p_{b}^{1}+p_{c}^{1}} \otimes\left[p_{b}^{2} \otimes\left(\tilde{t}_{a} \oplus \tilde{t}_{b}\right) \oplus\left(1-p_{b}^{2}\right) \otimes\left(\tilde{t}_{a} \oplus \tilde{t}_{b} \oplus \tilde{t}_{c}\right)\right] \\
\oplus \frac{p_{c}^{1}}{p_{b}^{1}+p_{c}^{1}} \otimes\left[p_{c}^{2} \otimes\left(\widetilde{t}_{a} \oplus \tilde{t}_{c}\right) \oplus\left(1-p_{c}^{2}\right) \otimes\left(\tilde{t}_{a} \oplus \tilde{t}_{b} \oplus \tilde{t}\right)\right]
\end{array}\right)\right] .
\end{aligned}
$$

Similarly, other branches ( $c$ and $b$ ) can be computed. As the result, duration of equivalent branch is

$$
\tilde{t}_{T_{p}}=\left[\begin{array}{l}
\frac{p_{a}^{1}}{p_{a}^{1}+p_{b}^{1}+p_{c}^{1}} \otimes\left[\tilde{t}_{a} \oplus\left(1-p_{a}^{2}\right) \otimes\left(\frac{p_{b}^{1}}{p_{b}^{1}+p_{c}^{1}} \otimes\left(\widetilde{t}_{b} \oplus\left(1-p_{b}^{2}\right) \otimes \widetilde{t}_{c}\right) \oplus \frac{p_{c}^{1}}{p_{b}^{1}+p_{c}^{1}} \otimes\left(\widetilde{t}_{c} \oplus\left(1-p_{c}^{2}\right) \otimes \widetilde{t}_{b}\right)\right)\right] \\
\oplus \frac{p_{b}^{1}}{p_{a}^{1}+p_{b}^{1}+p_{c}^{1}} \otimes\left[\widetilde{t}_{b} \oplus\left(1-p_{b}^{2}\right) \otimes\left(\frac{p_{a}^{1}}{p_{a}^{1}+p_{c}^{1}} \otimes\left(\widetilde{t}_{a} \oplus\left(1-p_{a}^{2}\right) \otimes \widetilde{t}_{c}\right) \oplus \frac{p_{c}^{1}}{p_{a}^{1}+p_{c}^{1}} \otimes\left(\widetilde{t}_{c} \oplus\left(1-p_{c}^{2}\right) \otimes \widetilde{t}_{a}\right)\right)\right] \\
\oplus \frac{p_{c}^{1}}{p_{a}^{1}+p_{b}^{1}+p_{c}^{1}} \otimes\left[\tilde{t}_{c} \oplus\left(1-p_{c}^{2}\right) \otimes\left(\frac{p_{a}^{1}}{p_{a}^{1}+p_{b}^{1}} \otimes\left(\tilde{t}_{a} \oplus\left(1-p_{a}^{2}\right) \otimes \widetilde{t}_{b}\right) \oplus \frac{p_{b}^{1}}{p_{a}^{1}+p_{b}^{1}} \otimes\left(\tilde{t}_{b} \oplus\left(1-p_{b}^{2}\right) \otimes \widetilde{t}_{a}\right)\right)\right]
\end{array}\right] .
$$




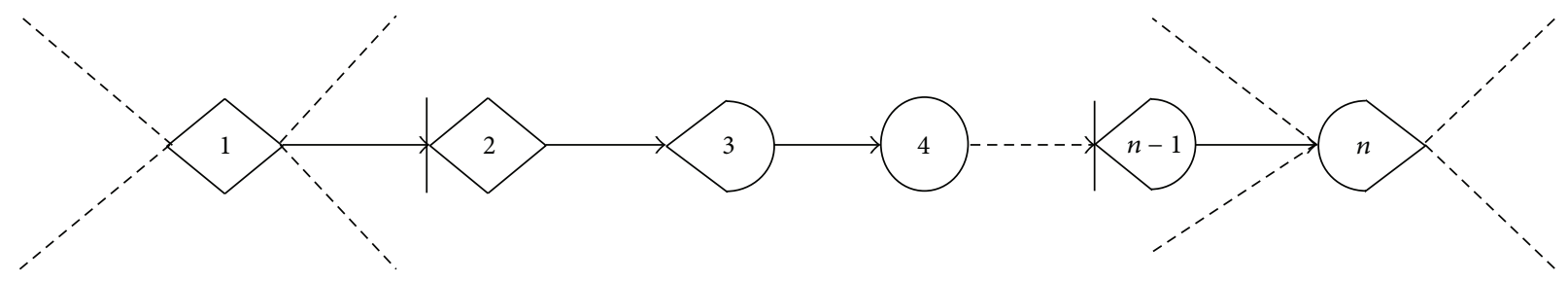

Figure 3: A display of series branches.

TABLE 2: Success probability of each branch from node (i).

\begin{tabular}{lcc}
\hline $\begin{array}{l}\text { Qyt. of branch }(i i) \\
\text { occurrence }\end{array}$ & $\begin{array}{c}\text { Occurrence } \\
\text { probability }\end{array}$ & $\begin{array}{c}\text { Success probability } \\
\text { of branch }(i-j)\end{array}$ \\
\hline 0 & $1-p_{i i}^{1}$ & $p_{i j}^{2}$ \\
1 & $p_{i i}^{1} \cdot\left(1-p_{i i}^{1}\right)$ & $p_{i j}^{2} \cdot\left(p_{i i}^{2}\right)$ \\
2 & $\left(p_{i i}^{1}\right)^{2} \cdot\left(1-p_{i i}^{1}\right)$ & $p_{i j}^{2} \cdot\left(p_{i i}^{2}\right)^{2}$ \\
$\vdots$ & $\vdots$ & $\vdots$ \\
$N$ & $\left(p_{i i}^{1}\right)^{n} \cdot\left(1-p_{i i}^{1}\right)$ & $p_{i j}^{2} \cdot\left(p_{i i}^{2}\right)^{n}$ \\
$\vdots$ & $\vdots$ & $\vdots$ \\
\hline
\end{tabular}

Concerning occurrence probability and success probability of equivalent branch, since branches are parallel and independent, occurrence probability is equal to probabilities aggregation (14). For success probability, similar averaging trend with similar times is used and we have

$$
\begin{aligned}
& p_{T_{p}}^{1}=p_{a}^{1}+p_{b}^{1}+p_{c}^{1}, \\
& p_{T_{p}}^{2}=\left[p_{a}^{2}+\left(1-p_{a}^{2}\right)\left(p_{b}^{2}+\left(1-p_{b}^{2}\right) p_{c}^{2}\right)\right] .
\end{aligned}
$$

(2) Parallel Branches between Two Nodes with "Deterministic" Output and "Inclusive-Or" Input. In such case, it is assumed that there are three branches, $a, b$, and $c$, for an activity. All three branches start altogether and when one of them is concluded, the other shall be stopped.

As we see, to achieve equivalent activity time, first, the time of current branches are getting defuzzy (based on (16)).

Defuzzy operation is a reversing process which returns a fuzzy distance to its crisp number:

$$
d \widetilde{t}_{a}=\frac{\left(a_{1}+2 a_{2}+2 a_{3}+a_{4}\right)}{6} .
$$

Then, these activities will be sorted from the lowest to the highest based on defuzzy values. Now, we assign 1 for the lowest defuzzy value and mark other values:

$$
\text { Sor } \tilde{t}_{\min }\left(d \tilde{t}_{a}, d \widetilde{t}_{b}, d \tilde{t}_{c}\right)=\left(d \tilde{t}_{1}, d \widetilde{t}_{2}, d \widetilde{t}_{3}\right) \Longrightarrow \widetilde{t}_{1}, \widetilde{t}_{2}, \widetilde{t}_{3} \text {. }
$$

Therefore, we have

$$
\tilde{t}_{T_{p}}=p_{1}^{2} \otimes \tilde{t}_{1} \oplus\left(1-p_{1}^{2}\right) \otimes\left[p_{2}^{2} \otimes \tilde{t}_{2} \oplus\left(1-p_{2}^{2}\right) \otimes \tilde{t}_{3}\right] .
$$

Concerning occurrence probability and success probability, when activities are parallel and independent, occurrence probability is equal to the aggregation of standardized probabilities and success probability is a similar trend to activities duration:

$$
\begin{aligned}
& p_{T_{p}}^{1}=1, \\
& p_{T_{p}}^{2}=p_{1}^{2}+\left(1-p_{1}^{2}\right)\left[p_{2}^{2}+\left(1-p_{2}^{2}\right) p_{3}^{2}\right] .
\end{aligned}
$$

(3) Parallel Branches between Two Nodes with "Deterministic" Output and "And" Input. Parallel branches show several activities. All these several activities must be performed and no processors or successor can be considered. When they are not fully conducted, it will not be possible to go to next step. So to achieve duration of equivalent branch, it is sufficient to use maximum fuzzy actor:

$$
\begin{gathered}
\tilde{t}_{T_{p}}=\max \left(\tilde{t}_{a}, \widetilde{t}_{b}, \widetilde{t}_{c}\right)=\left[\left(a_{1} \vee b_{1} \vee c_{1}\right),\left(a_{2} \vee b_{2} \vee c_{2}\right),\right. \\
\left.\left(a_{3} \vee b_{3} \vee c_{3}\right),\left(a_{4} \vee b_{4} \vee c_{4}\right)\right] .
\end{gathered}
$$

On the other hand, based on the approach, the success probability of equivalent branch resulted from multiple success probability of all activities (22), since all activities should be conducted to achieve the final event and to release the next node. Also as for the occurrence probability, since the activities are parallel and independent, the occurrence probability of equivalent branch is as follows:

$$
\begin{aligned}
& p_{T_{p}}^{2}=p_{a}^{2} \cdot p_{b}^{2} \cdot p_{c}^{2}, \\
& p_{T_{p}}^{1}=1 .
\end{aligned}
$$

4.2.3. Equivalent Making of Series Branches. A set of branches is called series when the path between their source nodes includes no diversion path $\left(S_{(i-j)}\right)$ (Figure 3 ). To estimate 3 
TABLE 3: Six states of parallel branches between two different nodes.

\begin{tabular}{|c|c|c|}
\hline State & Definition & Figure \\
\hline 1 & $\begin{array}{l}\text { Parallel branches between two nodes with "Probabilistic" output and } \\
\text { "Exclusive-Or" input }\end{array}$ & $\frac{a}{b}$ \\
\hline 2 & $\begin{array}{l}\text { Parallel branches between two nodes with "Deterministic" output and } \\
\text { "Inclusive-Or" input }\end{array}$ & $\frac{a}{b}$ \\
\hline 3 & $\begin{array}{l}\text { Parallel branches between two nodes with "Deterministic" output and } \\
\text { "And" input }\end{array}$ & $\frac{a}{b}$ \\
\hline 4 & $\begin{array}{l}\text { Parallel branches between two nodes with "Probabilistic" output and } \\
\text { "And" input }\end{array}$ & $a$ \\
\hline 5 & $\begin{array}{l}\text { Parallel branches between two nodes with "Deterministic" output and } \\
\text { "Exclusive-Or" input }\end{array}$ & $a$ \\
\hline 6 & $\begin{array}{l}\text { Parallel branches between two nodes with "Probabilistic" output and } \\
\text { "Inclusive-Or" input }\end{array}$ & $\frac{a}{b}$ \\
\hline
\end{tabular}

main parameters of equivalent branch $\left(\tilde{t}_{T_{s}}, p_{T_{s}}^{1}, p_{T_{s}}^{2}\right)$, a set of series branches is as follows:

$$
\begin{aligned}
\tilde{t}_{T_{s}} & =\sum_{k \in S_{(i-j)}} \oplus \tilde{t}_{k}=\left[\widetilde{t}_{(1-2)} \oplus \tilde{t}_{(2-3)} \oplus \cdots \oplus \tilde{t}_{[(n-1)-n]}\right], \\
p_{s}^{1} & =\prod_{k \in S_{(i-j)}} p_{k}^{1}=\left[p_{(1-2)}^{1} \times p_{(2-3)}^{1} \times \cdots \times p_{[(n-1)-n]}^{1}\right], \\
p_{T_{s}}^{2} & =\prod_{k \in S_{(i-j)}} p_{k}^{2} \\
& =p_{(1-2)}^{2} \times p_{(2-3)}^{2} \times p_{(3-4)}^{2} \times \cdots \times p_{((n-1)-n)}^{2} .
\end{aligned}
$$

4.2.4. Procedure of Removing Loops by Equivalent Making. Existence of reversible branches can be eventuated to form a loop and to execute one or several activities leading to delay and increase in time of progress and performance of activities (Figure 4). For removal of these loops and application of delay in a network, a fuzzy time and occurrence probability equivalent to that loop will be computed, and their impacts are applied to the activities affected by this loop.

Parameters equivalent to a loop are equal to parameters of equivalent branch to the paths between the two nodes of source $(o)$ and end $(m)$ of the loop. To get such values, the following steps can be assumed:

(1) In order to reduce amount of computations, first, the parallel and series branches between two nodes of $(o)$

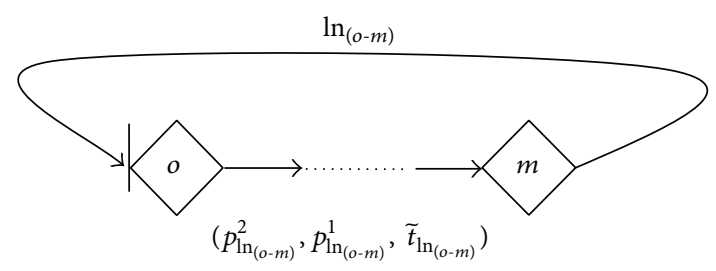

FIGURE 4: View of a loop formation.

and $(m)$ in the main network made, based on (13)(24), shall be equalized and shall be applied in the main graph.

(2) In the next stage, the set of branches and nodes between two nodes of $(o)$ and $(m)$, which play a role in connecting paths between these two nodes, shall be drawn based on the revised main network called $N_{\ln (o-m)}$ network.

(3) If the equivalent branch connecting two nodes of (o) and $(m)$ in $N_{\ln (o-m)}$ network is in a simple loop shape, we will go to step (5). However, if the loop is in a complex loop shape, then we will go to step (4).

(4) The reviewed complicated loops are of subindependent type in which all subsets of the main loop are in condition of independence relating to each other and the main loop. To start solution and application of 
a complex loop impact, the following shall be followed:

(a) Classification of the loops is as follows:

(i) To assume the main loop as a loop at zero level.

(ii) To classify the internal loops into two groups: (a) Level 1 simple loops and (b) Level 1 complex loops.

(iii) To classify the internal loops of Level 1 complex loops into two groups: (a) Level 2 simple loops and (b) Level 2 complex loops.

(iv) To continue the process of classification until levels of all loops are specified.

(b) Priority of the loops is as follows:

The main assumption on priority of loops shall be as follows:

The priority shall belong to loops in which the longest distance of their source node to last level source node involves the minimum rate.

(c) Selection and solution of reviewed loop based on rendered priority in step (b) are as follows:

First, the lowest classified level in the loop shall be prioritized and based on such priority, the loops of this level shall be solved in the selected complex loop, and their impacts shall be applied based on step (6). Then, process of prioritization shall be executed for the loop at one upper level in this complex loop. The related impacts shall be computed and applied on the basis of priority of the loops at this level of complex loop again. This process shall continue until reaching the main loop of the selected complex loop.

(d) Review of main loop is as follows:

After reviewing of all loops existing in Level 1 and application of their impacts, the impact of main loop of complex loop (Level zero) shall be computed and then we will go to step (5). Thus, the delay impacts resulting from existence of the loops (simple and complex) in the network can be applied, and their equivalent can be made and they shall be removed from the network.

(5) Based on the parameters of the branch equalized for the paths between nodes $(o)$ and $(m)$ $\left(\widetilde{t}_{(o-m)}, p_{(o-m)}^{1}, p_{(o-m)}^{2}\right)$ and parameters of reversible branch $\left(\tilde{t}_{(m-o)}, p_{(m-o)}^{1}, p_{(o-m)}^{2}\right)$, the parameters equivalent to the loop $\left(\widetilde{t}_{\ln _{(o-m)}}, p_{\ln _{(o-m)}}^{1}, p_{\ln _{(o-m)}}^{2}\right)$ can be computed as follows:

$$
\begin{aligned}
& \tilde{t}_{\ln _{(o-m)}}=\tilde{t}_{(o-m)} \oplus \tilde{t}_{(m-o)}, \\
& p_{\ln _{(o-m)}}^{1}=p_{(o-m)}^{1} \times p_{(m-o)}^{1}, \\
& p_{\ln _{(o-m)}}^{2}=p_{(o-m)}^{2} \times p_{(m-o)}^{2} .
\end{aligned}
$$

(6) For the application of the impacts of the loop $\left(\ln _{(o-m)}\right)$ in a network, after computing parameters of the loop, it would be assumed as a delay branch $(o o)$ on node (o), and its impacts will be applied as (26) in the network. It shall be noted that the impacts resulted from this loop shall be applied to parameters of time and success probability on the output branches from node $(o)$ :

$$
\begin{aligned}
\tilde{t}_{(k)}^{\prime}= & \tilde{t}_{(k)} \oplus\left[\left(\frac{p_{\ln _{(o-m)}}^{1}}{1-p_{\ln _{(o-m)}}^{1}}\right) \otimes \tilde{t}_{\ln _{(o-m)}}\right], \\
p_{(k)}^{2^{\prime}}= & p_{(k)}^{2} \cdot\left(1-p_{\ln _{(o-m)}}^{1}\right) \\
& \cdot\left[1+\left(\frac{p_{\ln _{(o-m)}}^{1} \cdot p_{\ln _{(o-m)}}^{2}}{1-p_{\ln _{(o-m)}}^{1} \cdot p_{\ln _{(o-m)}}^{2}}\right)\right] ;
\end{aligned}
$$

$$
\forall k \in Z_{Y_{o}}
$$

Also, to fix the probability of the occurrences in the output branches from node $(m)$, occurrence probability of these branches will be computed by the following, so that the sum of occurrence probability of output branches from node $(m)$ remains at one:

$$
p_{\left(k^{\prime}\right)}^{1^{\prime}}=p_{\left(k^{\prime}\right)}^{1}\left(1+\frac{p_{(m-o)}^{1}}{1-p_{(m-o)}^{1}}\right) ; \quad \forall k^{\prime} \in Z_{Y_{m}} .
$$

4.2.5. Proposed Algorithm to Resolve No-Loop Fuzzy Networks. Introduced problem solving method is based on equivalent making of parallel and series branches in each step of simplifying the fuzzy network and moving from the source node to the sink (end) node by surveying different paths between two nodes and to achieve a step in which only one equal branch is built between the two nodes of source and sink. Operation flowchart is shown in Figure 5.

\section{Application and Numerical Example: A Case Study}

This part of the project is conducted for the first time in a research institute without any ambiguity in defining the actions and estimating the time and probability of success was considered as an applied example. In addition to supporting model validity, one can also determine the deficiencies and even inabilities of current methods in treating with parallel 
paths and combining them with loops as well as drawing and resolving the network. According to Figure 6 and Table 4, the project network contains needed inputs to resolve the network.

$$
\left\{\begin{array}{l}
\ln _{(8-9)} \\
\text { Simple Loop }
\end{array} \mid\left\{\begin{array} { l } 
{ \operatorname { l n } _ { ( 1 - 1 6 ) } ^ { 0 } } \\
{ \text { Zero Levele } } \\
{ \text { Complex Loop } }
\end{array} \quad \left\{\begin{array}{l}
\ln _{(2-5)}^{1} \\
\text { Complex Loop }
\end{array}\right.\right.\right.
$$$$
\left\{\begin{array}{l|l}
\ln _{(3-5)}^{3} & \ln _{(11-12)}^{0} \\
\text { Simple Loop }
\end{array} \mid\left\{\begin{array}{l}
\text { Zero Levele } \\
\text { Complex Loop }
\end{array}\right.\right.
$$
as follows:
Summary of solution procedure based on the presented algorithm is as follows: classification and prioritization of the loops existing in the network, based on steps (a) and (b), are
In the first step and based on Section 4.2.4, we equalize (eliminate) loops and compute new values of parameters. Consequently, a network without any loops is obtained as seen in Figure 7 as well as new input parameters based on Table 5 .

After three times, the network without loop (Figure 7) will be simplified by equivalent making of series and parallel branches (based on Sections 4.2.2 and 4.2.3), we have:

$$
\begin{aligned}
& T_{0-17}=(54.06,68.62,80.01,94.37) \\
& p_{0-17}^{1}=1.00 \\
& p_{0-17}^{2}=0.59
\end{aligned}
$$

Deterministic methods are used to schedule the project so that limitation in drawing the network is proportionate to actual realities (such as regressive and parallel paths). Therefore, there will be timescales with huge differences. To resolve output problem, fuzzy CPM is used (10.9). To compare outputs from proposed algorithm and other methods, average of duration is computed and percentage of deviation can be computed by real time of executing the project.

According to Table 6, there is a huge difference (over two times) between fuzzy CPM output and real time of project termination which indicates the inability of this method to schedule R\&D project. Likewise, the real time is almost in higher border of project interval from the proposed model.

It is noteworthy that the probability of project success was computable in none of the current methods while it was computable in the proposed model and its obtained value (for case study) was $59 \%$.

5.1. Sensitivity Analysis. In this paper, for sensitivity analysis, the impact of loops occurrence probability on the project completion time (PCT) and the success probability are examined. According to the logic of GERT with loops, it is expected that, with increasing the probability of loop occurrence, the PCT increases and the success probability decreases and vice versa. To do this, the loop number $5-3\left(\ln _{(3-5)}\right)$ is considered for sensitivity analysis. The results of the sensitivity analysis are shown in Table 7 and related charts (Figures 8 and 9). As can be seen, increase (decreases) in the probability of loop occurrence leeds to increase (decreases) in the PCT and decrease (increase) in the success probability.

\section{Algorithm and Model Validation}

To prove appropriate performance of the algorithm presented in this paper, the results obtained by 3 articles including scheduling of fuzzy GERT networks were selected and the proposed algorithm's output was compared with the outputs of the articles. These methods include Itakura's method [15], which is one of the first and most valid methods provided in this area (Figure 10), Gavareshki's method [1] (Table 8), and Hashemin's method [38] (Table 9), which are the latest proposed methods. Investigations revealed that the solutions found from the proposed algorithm in this paper were very close to those found by Itakura and also by Hashemin methods. Because the proposed algorithm covers more comprehensive forms of the network compared to the two methods mentioned, more efficiency of this algorithm can be confirmed.

In the article presented by Hashemin [38], arrival time at node 5 was regarded as the end of project time and was calculated as 5.94, 9.47, 15.59, and 19.35. By comparing the two solutions, it can be seen that the proposed algorithm is close to Hashemin's solution, and the two can be assumed equal. Consequently, the two algorithms in solving the problem have an equal performance.

However, Hashemin's method [38] is only suitable for special states of fuzzy GERT networks with specific nodes (nodes with Exclusive-or receiver and Exclusive-or emitter), without loops and delay branches, while the proposed algorithm in this paper covers a wide range of networks.

\section{Conclusion and Future Research}

In this paper, it is attempted to make a brief study within an applied comparison on some of introduced techniques, by making a historical review on estimation of PCT in condition of having uncertainty in the activities network, duration, and path. As it is mentioned, most of papers and scientific works have been performed on two fields of fuzzy and probability. Researchers have solved problem of estimating time under uncertain conditions, directly regarding to two above-mentioned approaches or through combining them with linear and nonlinear planning models and simulation or through innovative solutions. Generally, in the conducted study, it can be concluded that most of performed works are related to estimations under network, and the best networks 


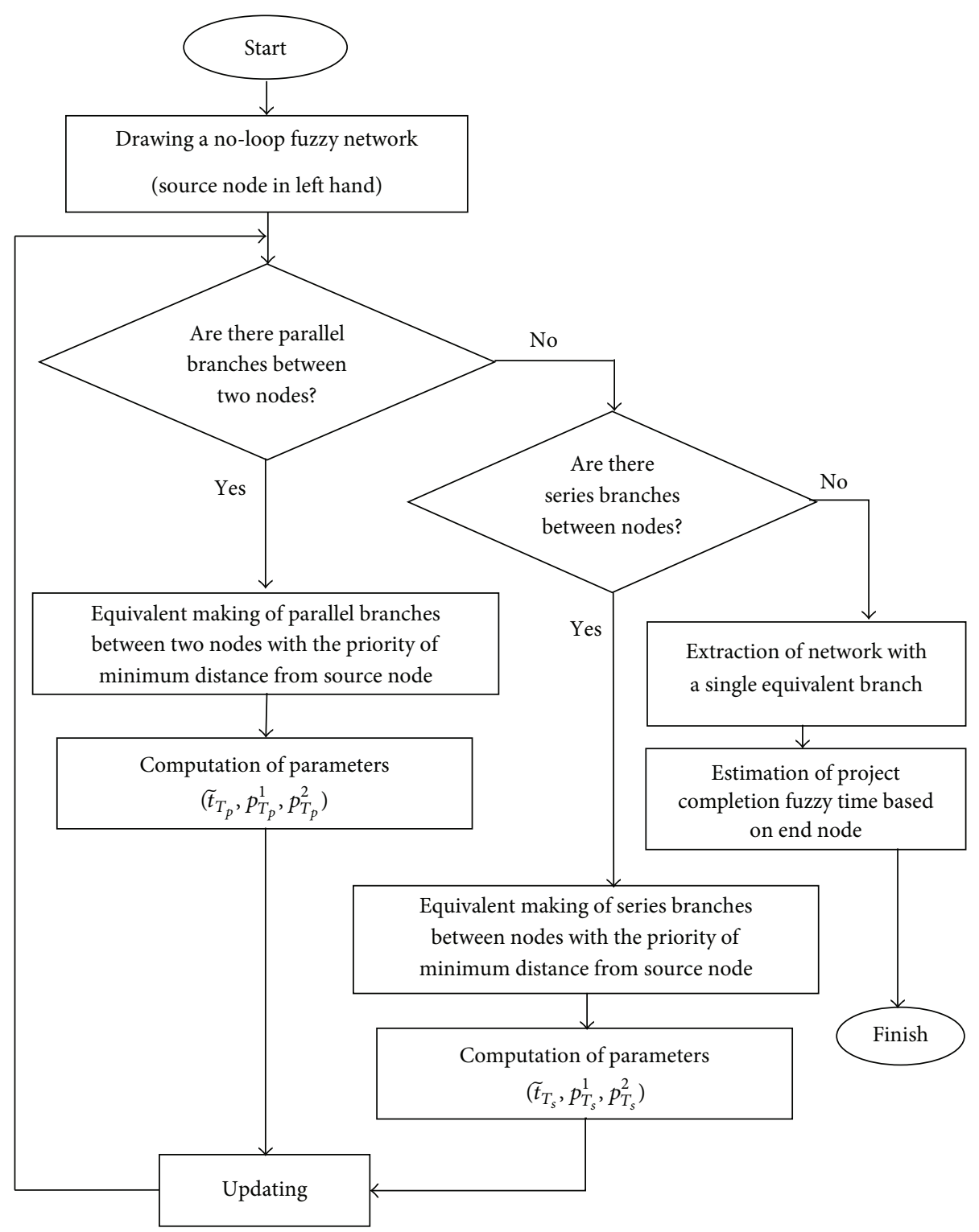

FIGURE 5: The proposed algorithm to resolve no-loop fuzzy networks.

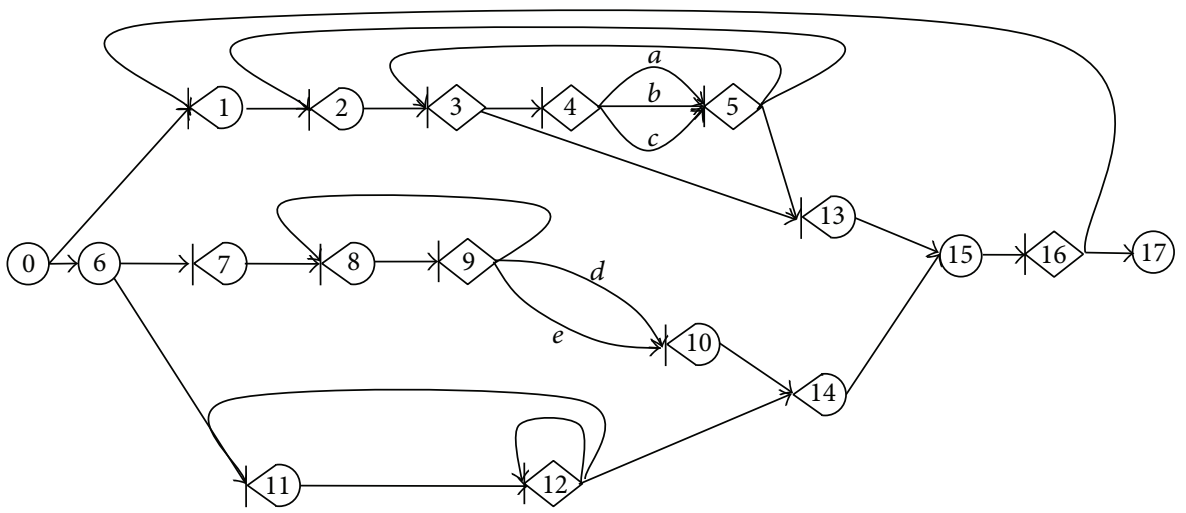

FIGURE 6: Activity network of the R\&D project. 
TABLE 4: Input parameters of activity network.

\begin{tabular}{|c|c|c|c|}
\hline Code of activity & Duration (week) & Success probability of activity/loop & Occurrence probability of activity/loop \\
\hline $0-1$ & $(4,5,6,7)$ & 1 & 1 \\
\hline $1-2$ & $(7,9,10,11)$ & 0.9 & 1 \\
\hline $2-3$ & $(2,3,4,5)$ & 0.9 & 1 \\
\hline $3-4$ & $(8,9,10,11)$ & 0.85 & 0.6 \\
\hline $3-13$ & $(12,14,15,18)$ & 0.8 & 0.4 \\
\hline $4-5(a)$ & $(2,3,4,5)$ & 0.8 & 0.7 \\
\hline $4-5(b)$ & $(2,4,5,7)$ & 0.8 & 0.2 \\
\hline $4-5(c)$ & $(6,7,8,10)$ & 0.85 & 0.1 \\
\hline $5-3$ & $(0,0,0,0)$ & 1 & 0.4 \\
\hline $5-2$ & $(0,0,0,0)$ & 1 & 0.25 \\
\hline $5-13$ & $(1,2,2,3)$ & 0.9 & 0.35 \\
\hline $13-15$ & $(1,1,2,2)$ & 1 & 1 \\
\hline $0-6$ & $(4,5,6,8)$ & 1 & 1 \\
\hline $6-7$ & $(2,3,3,4)$ & 1 & 1 \\
\hline $7-8$ & $(4,5,6,7)$ & 0.95 & 1 \\
\hline $8-9$ & $(3,4,4,5)$ & 0.9 & 1 \\
\hline $9-8$ & $(0,0,0,0)$ & 1 & 0.4 \\
\hline $9-10(d)$ & $(3,4,5,6)$ & 0.9 & 0.25 \\
\hline $9-10(\mathrm{e})$ & $(2,4,5,7)$ & 0.8 & 0.35 \\
\hline $10-14$ & $(1,1,1,1)$ & 1 & 1 \\
\hline $6-11$ & $(2,3,3,4)$ & 1 & 1 \\
\hline $11-12$ & $(6,7,8,9)$ & 0.8 & 1 \\
\hline $12-11$ & $(0,0,0,0)$ & 1 & 0.3 \\
\hline $12-12$ & $(1,2,3,3)$ & 1 & 0.35 \\
\hline $12-14$ & $(1,2,2,3)$ & 0.9 & 0.35 \\
\hline $14-15$ & $(2,3,4,4)$ & 1 & 1 \\
\hline $15-16$ & $(4,5,6,7)$ & 1 & 1 \\
\hline $16-1$ & $(0,0,0,0)$ & 1 & 0.2 \\
\hline $16-17$ & $(1,2,2,3)$ & 1 & 0.8 \\
\hline
\end{tabular}

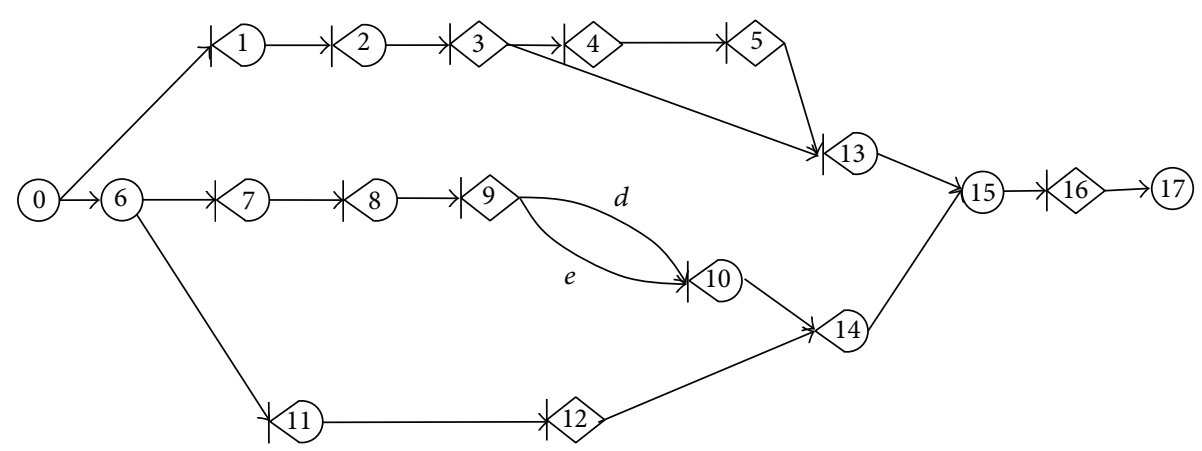

FIGURE 7: Activity network of the R\&D project without any loops.

have been developed for the uncertain conditions are related to the PERT and GERT networks.

Since use of probabilistic distribution techniques in the projects including large activity network and a dynamic environment full of uncertainty has been rather complicated, difficult, and limited, during the recent decades, attention to simulation and fuzzy approaches has been considerably intensified and development of techniques in these fields is expanded.
Therefore, in this paper, it is tried to merge fuzzy and probability techniques, in order to introduce a new approach to solve scheduling of projects having networks with parallel, series, and reversible cycle branches (RPFGERT) for estimating of PCT and success probability. To measure the validity of algorithm, a case study was solved and related results were presented in Section 5. Then, different methods were compared. Provided results in Section 6 show more accuracy and closeness to real time estimation. 
TABLE 5: Input parameters of activity network without any loops.

\begin{tabular}{|c|c|c|c|c|}
\hline $\begin{array}{l}\text { Code of } \\
\text { activity }\end{array}$ & $\begin{array}{l}\text { Initial fuzzy duration of } \\
\text { activity performance }\end{array}$ & $\begin{array}{l}\text { Final fuzzy duration of } \\
\text { activity performance }\end{array}$ & $\begin{array}{c}\text { Success probability } \\
\text { of activity }\end{array}$ & $\begin{array}{c}\text { Occurrence } \\
\text { probability of activity }\end{array}$ \\
\hline $0-1$ & $(4,5,6,7)$ & $(4,5,6,7)$ & 1 & 1 \\
\hline $1-2$ & $(7,9,10,11)$ & $(16.8,21.31,24.38,27.85)$ & 0.84 & 1 \\
\hline $2-3$ & $(2,3,4,5)$ & $(7.57,10.01,12.23,14.85)$ & 0.82 & 1 \\
\hline $3-4$ & $(8,9,10,11)$ & $(11.53,13.33,15.03,16.89)$ & 0.81 & 0.6 \\
\hline $3-13$ & $(12,14,15,18)$ & $(15.53,18.33,20.03,23.89)$ & 0.76 & 0.4 \\
\hline $4-5$ & $(3.17,4.71,5.94,7.66)$ & $(3.17,4.71,5.94,7.66)$ & 0.99 & 1 \\
\hline $5-13$ & $(1,2,2,3)$ & $(1,2,2,3)$ & 0.9 & 1 \\
\hline $13-15$ & $(1,1,2,2)$ & $(1,1,2,2)$ & 1 & 1 \\
\hline $0-6$ & $(4,5,6,8)$ & $(4,5,6,8)$ & 1 & 1 \\
\hline $6-7$ & $(2,3,3,4)$ & $(2,3,3,4)$ & 1 & 1 \\
\hline $7-8$ & $(4,5,6,7)$ & $(4,5,6,7)$ & 0.95 & 1 \\
\hline $8-9$ & $(3,4,4,5)$ & $(5,6.67,6.67,8.33)$ & 0.84 & 1 \\
\hline $9-10(d)$ & $(3,4,5,6)$ & $(3,4,5,6)$ & 0.9 & 0.42 \\
\hline $9-10(e)$ & $(2,4,5,7)$ & $(2,4,5,7)$ & 0.8 & 0.58 \\
\hline $10-14$ & $(1,1,1,1)$ & $(1,1,1,1)$ & 1 & 1 \\
\hline $6-11$ & $(2,3,3,4)$ & $(2,3,3,4)$ & 1 & 1 \\
\hline $11-12$ & $(6,7,8,9)$ & $(8.91,10.6,12.29,13.73)$ & 0.68 & 1 \\
\hline $12-14$ & $(1,2,2,3)$ & $(1.54,3.08,3.62,4.62)$ & 0.9 & 1 \\
\hline $14-15$ & $(2,3,4,4)$ & $(2,3,4,4)$ & 1 & 1 \\
\hline $15-16$ & $(4,5,6,7)$ & $(4,5,6,7)$ & 1 & 1 \\
\hline $16-17$ & $(1,2,2,3)$ & $(1,2,2,3)$ & 1 & 1 \\
\hline
\end{tabular}

TABLE 6: Comparative results and percentage of deviation.

\begin{tabular}{lccc}
\hline & Fuzzy duration (week) & Average of duration (month) & Percentage of deviation \\
\hline Fuzzy CPM & $(34,44,50,59)$ & 10.9 & $\mathbf{5 4 . 2}$ \\
Proposed model & $(54.1,62.8,80,94.4)$ & 17.3 & $\mathbf{2 7 . 3}$ \\
Real completion time & $(102,102,102,102)$ & 23.8 & - \\
\hline
\end{tabular}

TABLE 7: Results of sensitivity analysis.

\begin{tabular}{lcc}
\hline $\begin{array}{l}\text { Variation percentage } \\
\text { of occurrence } \\
\text { probability }\end{array}$ & $\begin{array}{c}\text { Variation } \\
\text { percentage of } \\
\text { the PCT }\end{array}$ & $\begin{array}{c}\text { Variation } \\
\text { percentage of } \\
\text { success probability }\end{array}$ \\
\hline$-70 \%$ & $-14.4 \%$ & $6.3 \%$ \\
$-50 \%$ & $-11.3 \%$ & $4.9 \%$ \\
$-30 \%$ & $-7.4 \%$ & $3.2 \%$ \\
$-10 \%$ & $-2.8 \%$ & $1.2 \%$ \\
$10 \%$ & $3.2 \%$ & $-1.4 \%$ \\
$30 \%$ & $11.2 \%$ & $-5.1 \%$ \\
$50 \%$ & $22.9 \%$ & $-10.2 \%$ \\
$70 \%$ & $43.0 \%$ & $-18.6 \%$ \\
\hline
\end{tabular}

Thus, the problems about estimating duration of research or $\mathrm{R} \& \mathrm{D}$ projects can be solved in a better way. It is also resolvable and proper. The complexities existing in other techniques are highly prevented. The proposed algorithm will be able to extend for different types of probabilistic and deterministic nodes, with probable and certain inputs and outputs in future.
TABLE 8: Proposed algorithm's results, Gavareshki method's results, and CPM solution.

\begin{tabular}{lcc}
\hline $\begin{array}{l}\text { Proposed algorithm's } \\
\text { result }\end{array}$ & $\begin{array}{c}\text { Gavareshki method's } \\
\text { result }\end{array}$ & $\begin{array}{c}\text { CPM } \\
\text { solution }\end{array}$ \\
\hline$(3.6,4.5,4.5,6.3)$ & $(4.5,6.5,6.5,10.6)$ & 3.5 \\
\hline \multicolumn{4}{c}{ TABLE 9: Results of Hashemin's solution. } \\
\hline Activity & Fuzzy duration of activity & $\begin{array}{c}\text { Occurrence } \\
\text { probability of activity }\end{array}$ \\
\hline $0-5$ & $(6.06,9.90,16.13,19.74)$ & 0.121 \\
$0-7$ & $(5.67,10.04,15.52,19.31)$ & 0.879 \\
\hline
\end{tabular}

Meanwhile, using different parallel paths between nodes of the above-mentioned types could be solved.

In future, proposed algorithm (method) would need research and development in the below areas:

(i) On complex loops, yet is opportunity for more research and development on subdependent complex loops. 


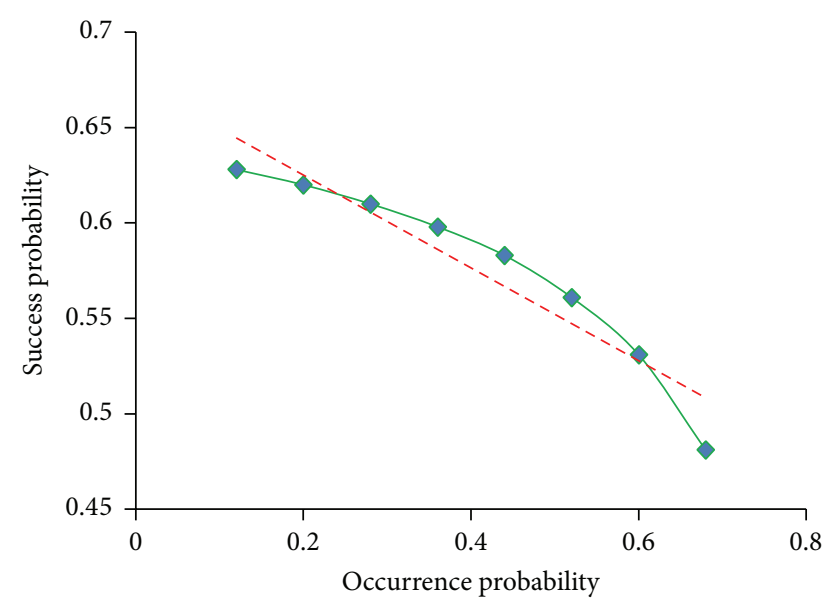

FIGURE 8: Impact of variation probability of loop occurrence on success probability.

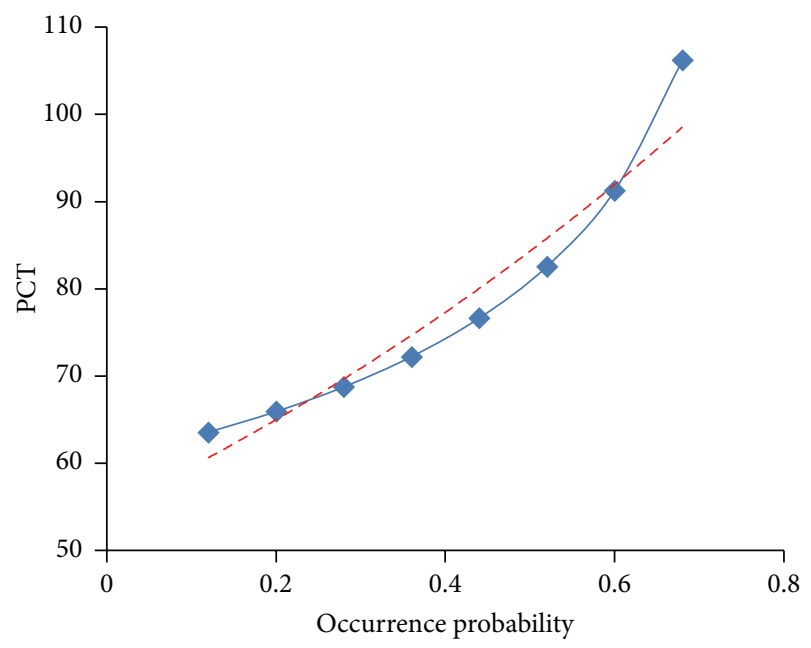

FIGURE 9: Impact of variation probability of loop occurrence on the PCT.

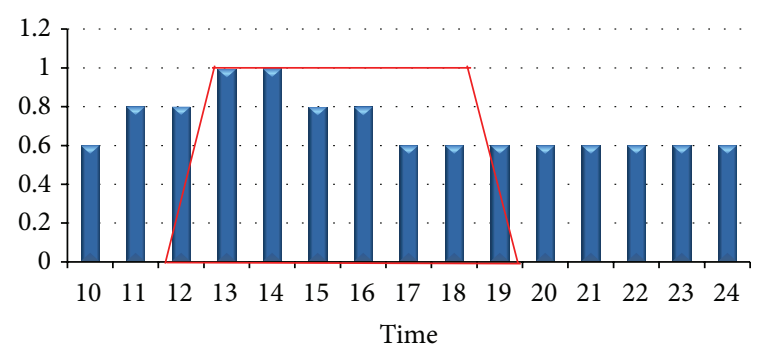

FIGURE 10: Fuzzy time of Itakura and the proposed algorithm.

(ii) One can work on changing provided algorithm to flowcharts and create software.

(iii) It is possible to use fuzzy numbers in estimating occurrence probability of activities and loops instead of probabilistic functions.

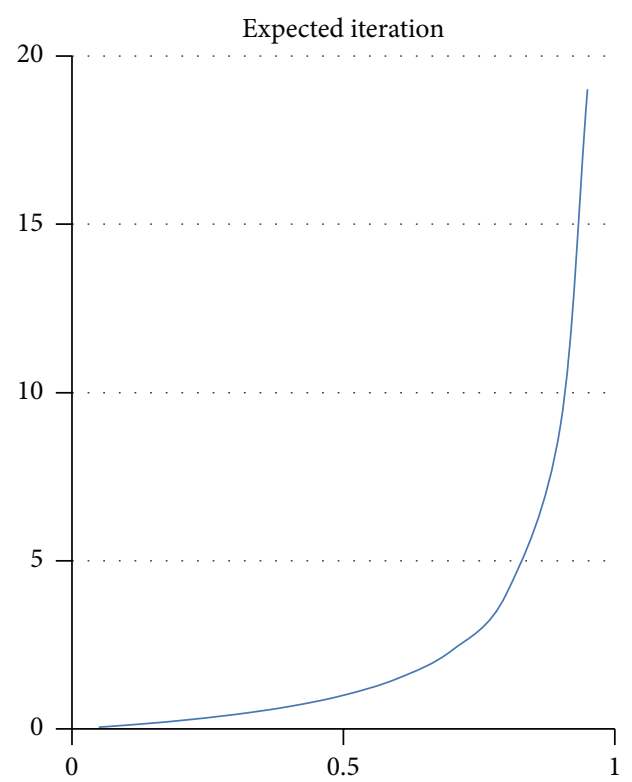

FIGURE 11

(iv) One can use analysis of sensitivity and update scheduling of activities network with loops.

(v) To estimate cost of each activity and project completion based on the proposed algorithm.

\section{Conflict of Interests}

The authors declare that there is no conflict of interests regarding the publication of this paper.

\section{References}

[1] M. H. K. Gavareshki, "New fuzzy GERT method for research projects scheduling," in Proceedings of the IEEE International Engineering Management Conference (IEMC '04), pp. 820-824, Singapore, October 2004.

[2] R. Lachmayer, M. Afsari, and R. Hassani, "C\# method for all types of nodes in fuzzy GERT," International Journal of Artificial Intelligence and Neural Networks, vol. 5, no. 1, pp. 57-62, 2015.

[3] D. Ivanov and B. Sokolov, Adaptive Supply Chain Management, Springer, London, UK, 2010.

[4] C. You, "On the convergence of uncertain sequences," Mathematical and Computer Modelling, vol. 49, no. 3-4, pp. 482-487, 2009.

[5] B. Liu, "Some research problems in uncertainty theory," Journal of Uncertain Systems, vol. 3, no. 1, pp. 3-10, 2009.

[6] N. Kuznetsov, "Managing the company in the setting of implementing large-scale development programs," Asian Social Science, vol. 11, no. 1, pp. 193-2003, 2015.

[7] K. Oyama, G. Learmonth, and R. Chao, "Applying complexity science to new product development: modeling considerations, extensions, and implications," Journal of Engineering and Technology Management, vol. 35, pp. 1-24, 2015.

[8] P. Patanakul, A. J. Shenhar, and D. Z. Milosevic, "How project strategy is used in project management: cases of new product development and software development projects," Journal of 
Engineering and Technology Management, vol. 29, no. 3, pp. 391414, 2012.

[9] A. A. B. Pritsker and G. E. Whitehouse, "GERT: graphical evaluation and review technique part II, probabilistic and industrial engineering applications," Journal of Industrial Engineering, vol. 17, no. 6, pp. 293-301, 1966.

[10] A. A. B. Pritsker and W. W. Happ, "GERT: graphical evaluation and review technique part I. Fundamentals," Journal of Industrial Engineering, vol. 17, no. 5, pp. 267-274, 1966.

[11] A. A. B. Pritsker, Modeling and Analysis Using Q-GERT Networks, Halsted Press, New York, NY, USA, 1977.

[12] L. A. Zadeh, "Fuzzy sets," Information and Computation, vol. 8, pp. 338-356, 1965.

[13] S. Chanas and J. Kamburowski, "The use of fuzzy variables in PERT," Journal of Fuzzy Sets and Systems, vol. 5, no. 1, pp. 11-19, 1981.

[14] I. Gazdik, "Fuzzy-network planning-FNET," IEEE Transactions on Reliability, vol. 32, no. 3, pp. 304-313, 1983.

[15] H. Itakura and Y. Nishikawa, "Fuzzy network technique for technological forecasting," Fuzzy Sets and Systems, vol. 14, no. 2, pp. 99-113, 1984.

[16] C. S. McCahon, "Using Pert as an approximation of fuzzy project-network analysis," IEEE Transactions on Engineering Management, vol. 40, no. 2, pp. 146-153, 1993.

[17] C.-H. Cheng, "Fuzzy consecutive-k-out-of-n:F system reliability," Microelectronics Reliability, vol. 34, no. 12, pp. 1909-1922, 1994.

[18] C.-H. Cheng, "Fuzzy repairable reliability based on fuzzy GERT," Microelectronics Reliability, vol. 36, no. 10, pp. 1557-1563, 1996.

[19] S. H. Nasution, "Fuzzy critical path method," IEEE Transactions on Systems, Man and Cybernetics, vol. 24, no. 1, pp. 48-57, 1994.

[20] S. Chang, Y. Tsujimura, and T. Tazawa, "An efficient approach for large scale project planning based on fuzzy Delphi method," Fuzzy Sets and Systems, vol. 76, no. 3, pp. 277-288, 1995.

[21] M. F. Shipley, A. De Korvin, and K. Omer, "A fuzzy logic approach for determining expected values: a project management application," Journal of the Operational Research Society, vol. 47, no. 4, pp. 562-569, 1996.

[22] J. R. Wang, "Fuzzy set approach to activity scheduling for product development," Journal of the Operational Research Society, vol. 50, no. 12, pp. 1217-1228, 1999.

[23] J. Wang, "A fuzzy project scheduling approach to minimize schedule risk for product development," Fuzzy Sets and Systems, vol. 127, no. 2, pp. 99-116, 2002.

[24] J. R. Wang, "A fuzzy robust scheduling approach for product development projects," European Journal of Operational Research, vol. 152, no. 1, pp. 180-194, 2004.

[25] J. J. Buckley, "Further results for the linear fuzzy controller," Kybernetes, vol. 18, no. 5, pp. 48-55, 1989.

[26] S. Chanas and P. Zielinski, "Critical path analysis in the network with fuzzy activity times," Journal of Fuzzy Sets and Systems, vol. 122, no. 2, pp. 195-204, 2001.

[27] C.-T. Chen and S.-F. Huang, "Applying fuzzy method for measuring criticality in project network," Information Sciences, vol. 177, no. 12, pp. 2448-2458, 2007.

[28] S.-P. Chen and Y.-J. Hsueh, "A simple approach to fuzzy critical path analysis in project networks," Applied Mathematical Modelling, vol. 32, no. 7, pp. 1289-1297, 2008.
[29] J. Fortin, P. Zielinski, D. Dubois, and H. Fargier, "Criticality analysis of activity networks under interval uncertainty," Journal of Scheduling, vol. 13, no. 6, pp. 609-627, 2010.

[30] H. Ke and B. Liu, "Fuzzy project scheduling problem and its hybrid intelligent algorithm," Applied Mathematical Modelling, vol. 34, no. 2, pp. 301-308, 2010.

[31] W. Huang, S.-K. Oh, and W. Pedrycz, "A fuzzy time-dependent project scheduling problem," Information Sciences, vol. 246, pp. 100-114, 2013.

[32] A. P. Shibanov, "Finding the distribution density of the time taken to fulfill the GERT network on the basis of equivalent simplifying transformations," Automation and Remote Control, vol. 64, no. 2, pp. 279-287, 2003.

[33] S. S. Hashemin and S. M. T. Fatemi Ghomi, "A hybrid method to find cumulative distribution function of completion time of GERT networks," Journal of Industrial Engineering International, vol. 1, pp. 1-9, 2005.

[34] K. Kurihara and N. Nishiuchi, "Efficient Monte Carlo simulation method of GERT-type network for project management," Computers and Industrial Engineering, vol. 42, no. 2-4, pp. 521531, 2002.

[35] K. Kurihara, N. Nishiuchi, M. Nagai, and K. Masuda, "Branching probabilities planning of stochastic network for project duration planning," in Proceedings of the IEEE Conference on Emerging Technologies and Factory Automation (ETFA '06), pp. 1333-1339, Prague, Czech Republic, September 2006.

[36] R. Lachmayer, M. Afsari, and B. Sauthoff, "Fuzzy GERT method for Scheduling research projects," in Proceedings of the 9th International Industrial Engineering Conference, pp. 1-7, Tehran, Iran, 2013.

[37] R. Lachmayer and M. Afsari, "Matlab method for exclusiveor nodes in fuzzy GERT networks," World Academy of Science, Engineering and Technology, Computer and Information Engineering, vol. 2, no. 1, 2015.

[38] S. S. Hashemin, "Fuzzy completion time for alternative stochastic networks," Journal of Industrial Engineering International, vol. 6, no. 11, pp. 17-22, 2010.

[39] Q. Shi and T. Blomquist, "A new approach for project scheduling using fuzzy dependency structure matrix," International Journal of Project Management, vol. 30, no. 4, pp. 503-510, 2012.

[40] H. C. Martínez León, J. A. Farris, G. Letens, and A. Hernandez, "An analytical management framework for new product development processes featuring uncertain iterations," Journal of Engineering and Technology Management, vol. 30, no. 1, pp. 45-71, 2013.

[41] H. C. M. Leon, J. A. Farris, and G. Letens, "Improving product development through front-loading and enhanced iteration management," in Proceedings of the Industrial Engineering Research Conference, Reno, Nev, USA, May 2011.

[42] M. T. Hajiali, M. R. Mosavi, and K. Shahanaghi, "Estimation of project completion time-based on a mixture of expert in an interactive space," Modern Applied Science, vol. 8, no. 6, pp. 229237, 2014.

[43] K. Shahanaghi and M. T. Hajiali, "Estimation of project time and cost at completion using fuzzy Kalman filter and ARMA model," Management, Business and Economics, vol. 2, no. 1, 2014.

[44] M. Verma and K. K. Shukla, "A new algorithm for solving fuzzy constrained shortest path problem using intuitionistic fuzzy numbers," International Journal of Artificial Intelligence and Neural Networks, vol. 5, no. 1, pp. 38-42, 2015. 


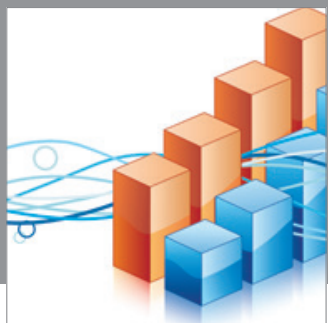

Advances in

Operations Research

mansans

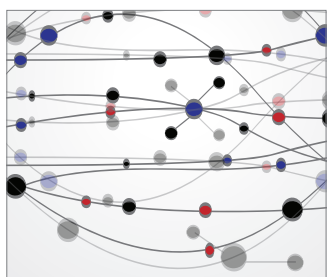

The Scientific World Journal
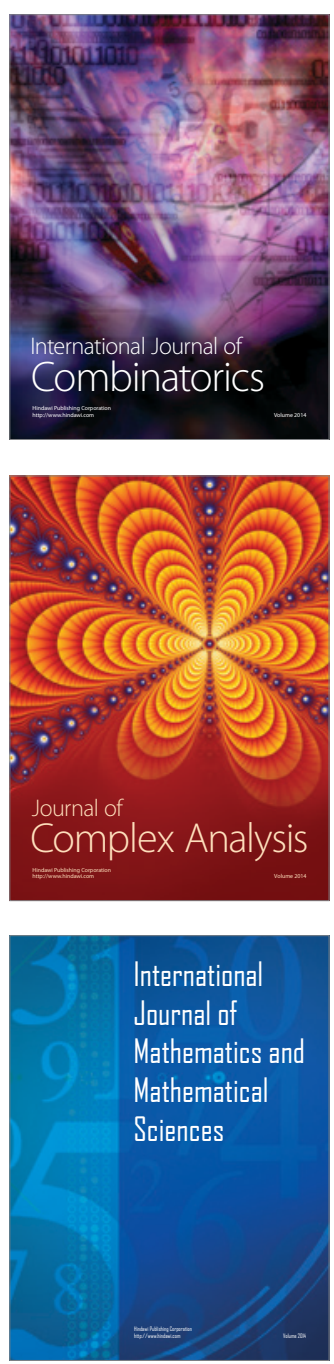
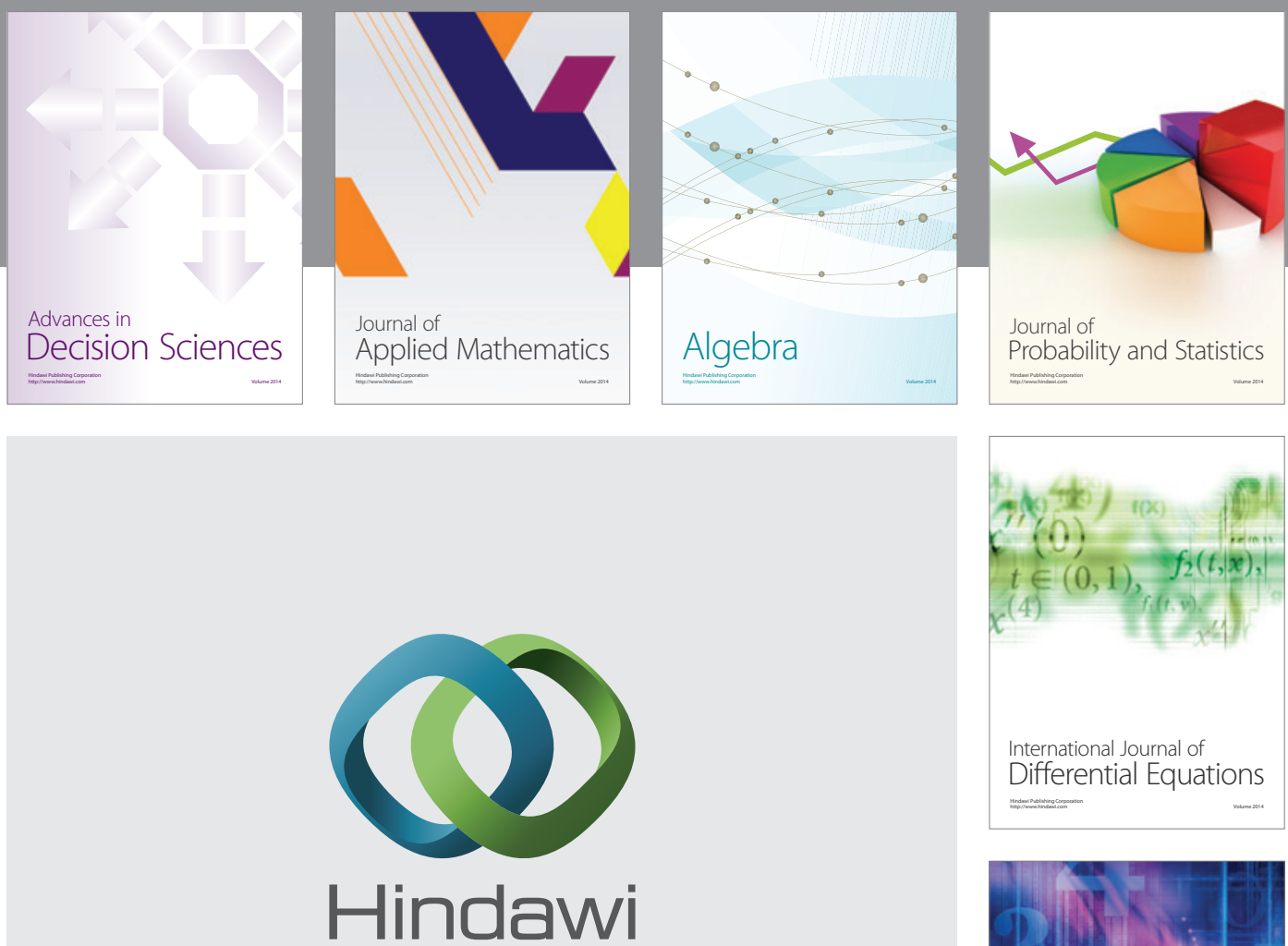

Submit your manuscripts at http://www.hindawi.com
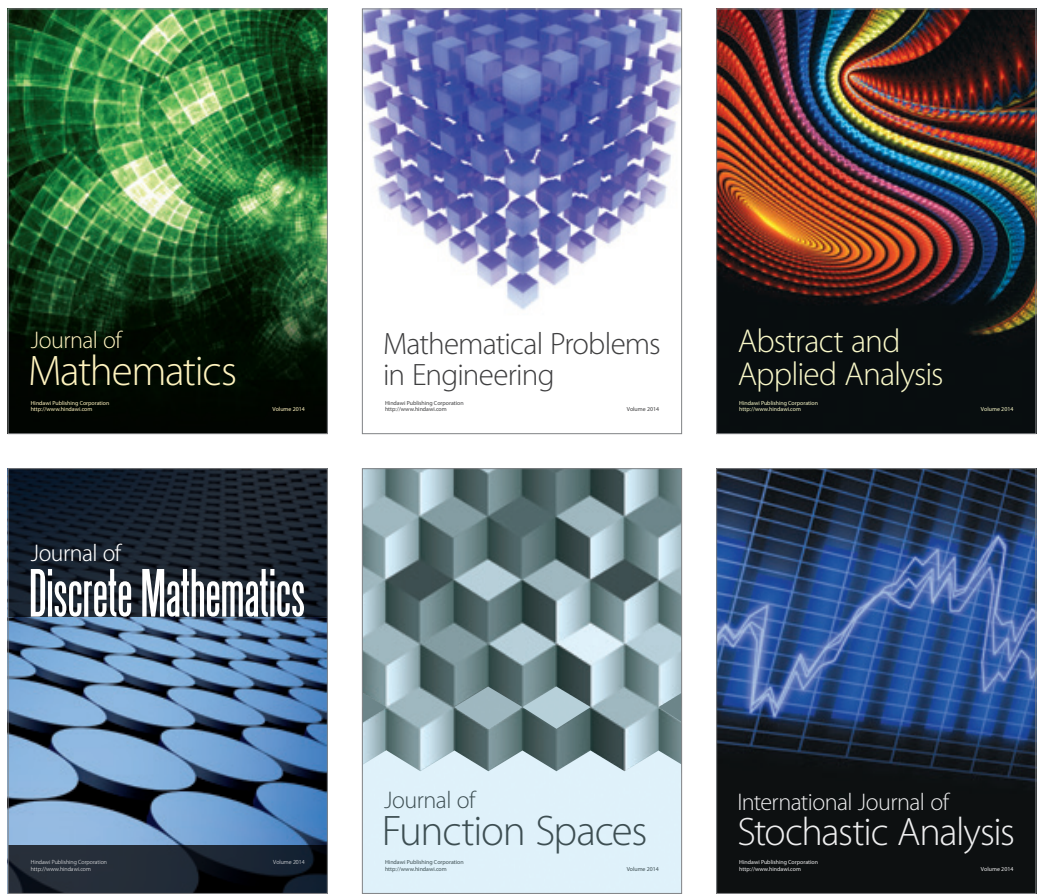

Journal of

Function Spaces

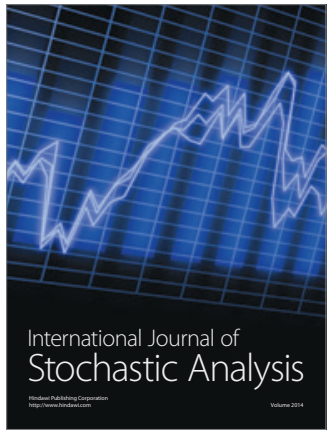

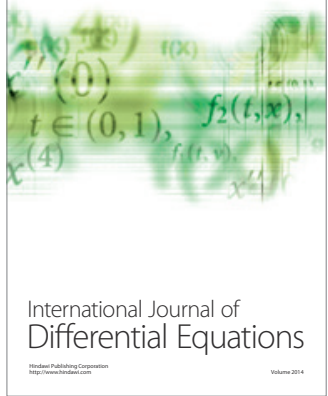
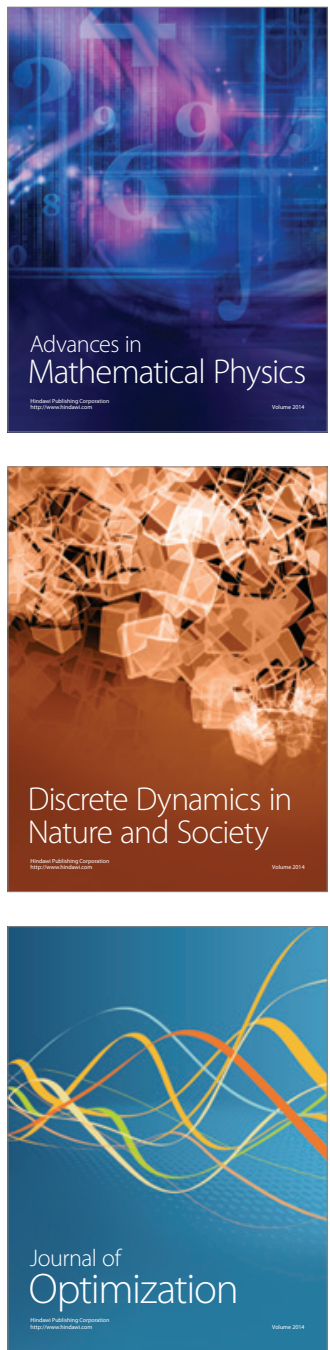